\title{
Recent Young Adult Sports Literature in Review
}

\section{GUT CHECK BY ERIK KESTER}

(Published in 2019 by Farrar Straus Giroux/Macmillan)

\section{LISA A. HAZLETT UNIVERSITY OF SOUTH DAKOTA}

The town of Grayport reveres football; Wyatt's brother, Brett, owns the field as its MVP while Wyatt is overweight and awkward, mostly ignored at school and home, and yearning for belonging and importance. After Brett's arm is broken during a nasty play he enters rehab; Wyatt struggles alongside, believing that making the team is his last chance to connect with his brother and be perceived for more than size in school. As they demolish opponents, deadly red tide emerges and ends Grayport's fishing season, ravishing its impoverished economy.

The boys' success and town collapse attract a media offer; if televised playing their arch-rivals, winning earns Grayport's recovery. This golden opportunity will force Wyatt's devastating decision, however, as Brett is hiding a severe concussion: should Wyatt prevent Brett's playing and destroy Grayport, or remain silent, risking Wyatt's scholarship, permanent disability, or even death?

Deftly narrated by likeable Wyatt, his self-deprecating humor, hilarious, spot-on commentary, and poignant insights should resonate with any self-conscious teen. The negative effects of small-town dependence upon athletic scholarships are harshly portrayed, although enabling the boys' closeness. Wyatt's realization of liking oneself and including others for a larger life is equally applicable to Brett, with moving to college rather than away from Grayport a reminder of commitment to heritage, family, and friends.

This story is compelling with a thrilling ending, but specifics are problematic; character development is sketchy, significant plotlines minimized, and implausible situations abound (the boys share a bunk bed, yet are virtual strangers). Contrivances glare; each time Wyatt nears penalties for 
poor choices or faces serious decisions, the miraculous occurs, solving the problem and neatly removing personal consequences (red tide's appearance buries his naïve newspaper interview; a stunning incident before televised game). The unanticipated adds exciting twists throughout, but seeing a troubled teen attempting to solve problems and learning from each seems equally captivating.

\section{HEROINE BY MINDY MCGINNIS}

(Published in 2019 by Katherine Tegen Books)

\section{ANN MARIE SMITH NORTH AMERICAN UNIVERSITY}

Mickey, a respected, first-string catcher, is looking forward to her senior year of high school when the softball team is predicted to win the state championship. Right before the season begins, Mickey and her best friend, Carolina, the team's star pitcher, are involved in a car accident.

As Mickey struggles with physical therapy and conditioning, she turns to Oxycotin to suppress her anxiety and physical pain. As her friendship with Carolina and other team members deteriorates, Mickey seeks companionship with opioid addicts.

Heroine is a realistic portrayal of a high school student's dependence on Oxycotin, and eventually heroin, in order to adapt to the physical and emotional demands of a team sport. A convincingly multidimensional character, Mickey narrates her process of addiction with humor and thoughtfulness. Readers will be drawn to Mickey's quest for identity and acceptance as her addiction obscures her judgement, isolating Mickey from the people who love her most. 


\section{HERE TO STAY BY SARA FARIZAN}

(Published in 2018 by Algonquin Young Readers)

\section{ANITA DUBROC LOUISIANA STATE UNIVERSITY}

Sara Farizan's Here to Stay throws the reader into competitive prep basketball while also tackling issues of parental death, cyberbullying, and asserting one's identity and heritage. Once Bijan Majidi is put into a varsity basketball game during the playoffs, he enters Granger School's popular crowd. The basketball team is slow to accept Bijan, but his talent makes him essential to their success, even while some players never become his friends. His popularity doesn't change him; he still reads comics and hangs out with his best friend, Sean. NBA players Reggie Miller and Kevin Harlan also give commentary on Bijan's life, acting as his internal voice. The book is loaded with 1980s pop culture references, so adults will enjoy the book too.

Bijan realizes that being in the spotlight is great for his social life. Elle, the girl he likes is finally noticing him. However, he is also the target of a cyberbully attack accusing him of being a terrorist because he is Muslim and half-Persian and half-Jordanian. Through his new role on the varsity team, Bijan finds his strengths, both on and off the court. He discovers his voice and an unrealized support unit who helps him uncover who is behind the mysterious and hateful messages.

Farizan brings together so many issues in such a short book, yet each is handled with great sensitivity. Farizan's inclusion of a Middle Eastern, first-generation American student brings a muchneeded diversity to young adult literature. Happily, parents are visible and socially active in Farizan's story. There are a few references to Islam, specifically in scenes when Bijan must make a moral choice. The novel also speaks to families and teens becoming social activists, who will note how the Granger School's students stand up to cyberbullying and xenophobia in their school and community. The novel's quest to uncover the school's cyberbully largely divides the team, though in doing so, Bijan creates unlikely friendships. These friendships show how young people from different backgrounds and realities can come together for a common cause. In setting the novel at an elite private school, positioning Bijan as different from his classmates, and bringing in issues of race, Farizan draws parallels to Angie Thomas's The Hate U Give. 